\title{
OCCUPATIONAL SPECIFICS OF ELITE FEMALE HANDBALL PLAYERS IN RELATION TO INJURY RECOVERY, SOCIAL SUPPORT AND ENVIRONMENTAL FACTORS
}

\author{
MARTA BON and MOJCA DOUPONA \\ University of Ljubljana, Ljubljana, Slovenia \\ Faculty of Sport
}

\begin{abstract}
Objectives: The aim of the study was to analyze the injury characteristics, satisfaction with social support and environmental factors in elite female handball players in the injury recovery process. Material and Methods: The retrospective study combined quantitative (questionnaire) and qualitative (interview) methods, and presented 3 distinct perspectives, i.e., those of active players, former players and coaching staff members (SMs). The research sample in the first part consisted of 51 active professional female handball players (aged 26.3 \pm 2.6 years) with an injury history. The answers from an online questionnaire were processed according to basic statistical parameters (SPSS). The second part of the study included 9 semi-structured interviews, 6 with former players and 3 with coaching SMs. Results: All the 51 active players reported 140 injuries (on average 2.7 injuries/player) in the last 6 years. The recovery time ranged 1 day-10 months. No statistically significant differences were observed between the career length and anterior cruciate ligament tear $\left(\chi^{2}-3.18, p=0.53\right)$, and the career length and posterior cruciate ligament tear $\left(\chi^{2}-1.87 ; p=0.76\right)$. The former players' perceptions of social support and environmental factors are similar to the opinions expressed by the coaching SMs, while the active players held high expectations. The highest level of satisfaction with social support was reported for family members $(\mathrm{M} \pm \mathrm{SD} 4.35 \pm 0.814)$ and the physiotherapist $(\mathrm{M} \pm \mathrm{SD} 4.12 \pm 3.28)$, whereas the players were not very satisfied with the social support offered by the head coach (M \pm SD 2.73 \pm 0.75$)$. Coaching SMs considered providing social support as something that exceeded their competences. Conclusions: The analysis of the injury recovery process indicated a need for a new function in handball clubs - an expert with interdisciplinary competencies, who would contribute to faster recovery and general wellbeing of professional handball players. Int J Occup Med Environ Health. 2021;34(1):101-10
\end{abstract}

Key words:

recovery, social support, environment, female, injury, professional handball

\section{INTRODUCTION}

Professional sport is, according to the Standard Classification of Occupations of 2012 [1], an occupation placed among arts, entertainment and design. In the occupational theory, injuries are described as any type of injury or illness that occurs to individuals concerning his or her specific occupational demands or requirements [2].
The occupation of a professional team sports player involves certain specifics such as intensive public relations and worldwide media presence, extremely high budgets in some sports, special working conditions, shorter career paths and, above all, a high risk of injury [2,3,4-7]. Absence due to injury is one of the most stressful factors in professional sports. Sports science has been trying to bal-

Funding: this research was supported by Slovenian Research Agency (ARRS) (project No. P5-0147-0587 entitled "The kinesiology of mono-structured, poly-structured and conventional sports," project manager: Prof. Milan Čh).

Received: March 29, 2020. Accepted: September 24, 2020.

Corresponding author: Mojca Doupona, University of Ljubljana, Faculty of Sport, Gortanova 22, 1000 Ljubljana, Slovenia (e-mail: Mojca.doupona@fsp.uni-lj.si). 
ance this stress in the last few decades by contributing to the optimization of injury prevention [7-10] and injury recovery with intense research $[2-4,6,8,11-13]$. Since professional handball is one of the sports with the highest injury risk $[6,7,9,12,14-16]$, there is an increased focus on prevention training, especially in female handball, which has several specific features, from differences in the body composition and motor abilities to different emotional reactions [6,9,14].

A holistic approach to injury recovery is recommended in nearly all professional sports $[4,5,14,16]$. An aspect that greatly affects injury recovery concerns environmental factors, especially:

- physical factors: accessibility to recovery facilities and opportunities for recovery activities (hospitals, health centers, therapeutic centers, other medical and physical therapy equipment, gyms, SPAs, etc.);

- institutional support: receiving similar benefits during injury recovery as in the active status (full insurance).

Social support, the "experience of being valued, respected, cared about and loved by others," is a broad term encompassing a variety of constructs of extreme importance in sports rehabilitation $[5,6,17,18]$, and includes support perceptions (perceived support) and the receipt of supportive behaviors (received support) [17]. Social support can reduce stress, and improve physical and mental wellbeing, which is well documented in literature on sports and in general [15,16,19,20,22-24], as well as in specific sports coaching literature $[21,26,28,29]$. Hardy and Crace's typology [17] organizes social support exchanges into 3 main categories:

- emotional support (listening and comforting),

- informational support (discussing and acknowledging an injured athlete's status),

- tangible support (providing personal or material assistance).

This classification was also followed in some other studies $[15,18,19]$, including an examination of general and sport-specific social support research [22], which is mostly related to the above-mentioned specific features of elite sports (a special position in the society - public presence, extreme conditions and demands).

Injuries in professional sports constitute a topic that is widely analyzed from different perspectives [3-5,7,8], but not often from the occupational point of view. This study presents certain specific environmental factors which come at play during injury recovery in elite female handball, including a comparison of different viewpoints, which can lead to a better understanding of the occupation of an elite female handball player, as well as contribute to improved relationships between players and coaches, and their general well-being, and, consequently, yield better results in elite competitions.

\section{MATERIAL AND METHODS}

The retrospective study combined quantitative (questionnaire) and qualitative (interview) methods and presented 3 distinct perspectives, i.e., those of active players, former players and coaching staff members (SMs). In regard to the sample size, the total population is limited due to the special character of the examined population (injured players in elite female handball). A statistical analysis was applied to the injury and length of the career only, while descriptive measures were applied in general in the calculation of means and standard deviation.

The survey participants and interviewees were asked to evaluate the same club environment in 2010-2016.

The questionnaire for active players consisted of 4 parts (31 questions), including the socio-demographic data, injury characteristics, environmental factors and social support. In the social support part, following the methodology applied in some previous research studies [18,24], the authors used and adapted some questions from the Social Support Questionnaire (SSQ) [18], which is a quantitative and psychometrically sound questionnaire that was approved for public release in 1981. Some other 
studies $[15,18,19]$ reported that the SSQ is a reliable instrument for social support measurements with good testretest reliability and convergent internal construct validity. The answers were processed according to basic statistical parameters (SPSS).

The consensual qualitative research (CQR) [30] was used for the interviews as an inductive method that is characterized by open-ended interview questions (small samples, reliance on words over numbers), complemented by the strategy of substantive and theoretical coding.

The participants in the study were personally informed that they could refuse participation and withdraw from the study at any time, for any reason.

\section{The sample}

Three subsamples were used in the study: active players $(\mathrm{N}=51)$, coaching SMs $(\mathrm{N}=3)$, and former players $(\mathrm{N}=6)$.

\section{Active players}

With the permission of the club's officials and players, data about all injuries in the club in 2010-2016 were obtained through a special questionnaire, personal observation and conversation with the injured players. Out of the 62 injured players, the authors received 51 responses (body mass $\mathrm{M} \pm \mathrm{SD} 68.2 \pm 5.4 \mathrm{~kg}$, body height $\mathrm{M} \pm \mathrm{SD}$ $175.3 \pm 5.7 \mathrm{~cm}$ ), which represents $82.21 \%$ of all injured players in the analyzed period. At the time of data collection (2018), 10 of them were still playing for the said club; all the others were at the time members of different European clubs. The respondents played handball professionally for $\geq 3$ years, all having $\geq 1$ injury recovery period in the same environment. At the time of the study, the players were aged $19-38$ years ( $76.5 \%$ were in the age group of 20-30 years), practicing 7-10.5 h/week during a regular season. Normally, each season started with physical preparation (generally in August), which was followed by the competition season October-May, with 1.5 matches/ week on average. The season finished with the post-com- petition program and at least 1-month summer holidays, with some individual plans depending on career characteristics (age, injury history, the competition level, and the professional status).

\section{Coaching SMs}

The 3 coaching SMs were included in the study:

- the head coach (51 years old; 14 years of experience in professional handball);

- the strength and conditioning coach (36years old; 5 years of experience in professional handball);

- the physiotherapist (38 years old; 8 years of experience in professional handball).

All worked with the players included in the present study for 3-6 years (Table 1).

\section{Former players}

Interviews were conducted with 6 former players who had stopped playing $\geq 3$ years before and held a coaching SM position for $\geq 2$ years. All had played in the Champions League for $>6$ years and finished at least the first level of handball education. The former players were, at the time of the interview, on average $38.2 \pm 4.3$ years old, had $8.5 \pm 4.08$ years of experience in professional sports (max 12 years) and had played for $\geq 3$ years in the studied club environment. The injury characteristics and recovery period data were collected in the initial part of the study (Table 2).

\section{Procedure}

Active players

After several telephone conversations, invitations with an explanation of the purpose of the study and a short description of the basic terminology were sent to all (nearly 100) active players. The possibility of having a face-to-face or phone conversation to explain further details of the study was offered to all players, which resulted in 11 such conversations being held, while all the others provided their consent to cooperate without asking for further explana- 
Table 1. Age and experience of coaching staff members (SMs) in the study on assessing the injury recovery and social support among elite female handball players from the European Champions League, the University of Ljubljana, Slovenia, 2017-2021

\begin{tabular}{lccc}
\hline & Variable & \multicolumn{3}{c}{$\begin{array}{c}\text { Participants } \\
(\mathrm{N}=3)\end{array}$} \\
\cline { 2 - 4 } & $\begin{array}{c}\text { head coach } \\
\text { (coaching SM 1) }\end{array}$ & $\begin{array}{c}\text { physiotherapist } \\
\text { (coaching SM 2) }\end{array}$ & $\begin{array}{c}\text { strength and conditioning } \\
\text { coach (coaching SM 3) }\end{array}$ \\
\hline $\begin{array}{l}\text { Age [years] } \\
\text { Seniority [years] }\end{array}$ & 51 & 38 & 36 \\
$\quad$ elite handball & & & \\
in the club & 14 & 8 & 5 \\
\hline
\end{tabular}

Table 2. Injury and injury recovery characteristics of former players (FPs) in the study on assessing the injury recovery and social support among elite female handball players from the European Champions League, the University of Ljubljana, Slovenia, 2017-2021

\begin{tabular}{|c|c|c|c|c|}
\hline FP & $\begin{array}{c}\text { Age } \\
\text { [years] }\end{array}$ & $\begin{array}{c}\text { Elite } \\
\text { handball } \\
\text { seniority } \\
\text { [years] }\end{array}$ & Injury & Recovery period \\
\hline 1 & 36 & 11 & sprained ankle (10 times) & on average $>1$ month/season \\
\hline 2 & 42 & 13 & knee surgery ( 3 times), several minor injuries (sprains) & 10 months/season \\
\hline 3 & 44 & 3 & $\begin{array}{l}\text { knee surgery (twice), broken teeth, chronic shoulder } \\
\text { and hip problems }\end{array}$ & 7 months/season \\
\hline 4 & 32 & 5 & knee surgery (twice) & around 6 months - twice in the career \\
\hline 5 & 39 & 7 & sprained ankle ( $>10$ times, chronic) & 20 days each time \\
\hline 6 & 37 & 12 & shoulder surgery (twice) & 60 days each time \\
\hline
\end{tabular}

tion. After a positive response from the player, the process was continued by sending a link to an online questionnaire.

\section{Interview guide development}

Consistent with the CQR methodology, a semi-structured interview guide was developed based on a review of the existing research literature [30]. Throughout the interview, probes were included to elicit specific information. The first part collected socio-demographic data, the second social support characteristics, and the third environmental factors of injury recovery. All the interviewees were informed that they were free to proceed in the direction dictated by the conversation flow.
The next step was the phase of transcription: a member of the research team read through each transcript and constructed an initial thematic structure. A cross-analysis was performed to establish the frequencies for each category and to reconcile any differences before completing the data [30]. Finally, a stability check was performed to determine if the results generally explained the phenomenon of a group [30].

All steps in the testing procedure were conducted in accordance with the ethical standards of a responsible committee on the local human experimentation, and with the Helsinki Declaration as revised in 2013.

Clarification probes were made to ensure the accurate understanding. Each interview lasted 45-90 min. 


\section{Coaching SMs}

The interview questions were divided into 5 sets:

- personal experience with injured players;

- experience with providing social support:

o emotional support,

$\circ$ tangible support,

○ informational support;

- evaluation of the players' personal liability for injury and recovery;

- relationships between injured players and the coaching SMs;

- environmental factors in the club.

\section{Former players}

Former players were asked to:

- evaluate their satisfaction with the social support they received during their active career;

- elaborate the current active players' responses about the low level of social support provided by the coaching SMs;

- evaluate environmental conditions in the club relevant to the players' injury recovery;

- give a general overview of their experience with injuries and the recovery process in professional female handball.

\section{RESULTS}

The results are presented separately for all 3 subsamples: injury recovery and social support from the active players', former players' and coaching SMs' points of view.

\section{Active players}

The active players included in the survey (6 goalkeepers, 21 backs, 16 wings, and 8 line players) had played on average 8.51 years at the professional level throughout their career. The average age was 26.3 years. The active players had spent $0-4$ days in hospital $(\mathrm{M} \pm \mathrm{SD} 4 \pm 0.96)$ in 1 competition season, and 5 of them had spent $24 \mathrm{~h} /$ day in bed during the whole week. The players altogether $(\mathrm{N}=51)$ reported 140 injuries (2.74/1 player) in their career up to that point, with the longest recovery period of 10 months, and 18 days/season on average. Throughout their entire career, the respondents suffered mostly from sprained ankles (86.27\%), sprained fingers (50.98\%), and knee injuries $(88.23 \%$; including anterior cruciate ligament [ACL] tear, posterior cruciate ligament [PCL] tear, complete or partial lateral collateral ligament [LCL] tear, or meniscus tear). The ACL tear as the worst injury in their career was mentioned by $21.57 \%$ of the respondents, with only ankle sprain receiving a larger percentage $(25.49 \%)$.

No statistically significant differences were observed between the career length and ACL tear $\left(\chi^{2}-3.18, p=0.53\right)$, and the career length and PCL tear $\left(\chi^{2}-1.87, p=0.76\right)$. When analyzing injuries in 1 club which occurred in 2010-2016, the results revealed 19 injuries, with 4 sprained ankles (7.84\%) and no ACL or LCL tear. In addition, 4 players $(21.44 \%)$ were absent for $>4$ months, and 5 for around 1 month. In 12 cases (63.24\%), the injury occurred during the official match, and in $5(26.3 \%)$ during training. The players stated that the prevailing feeling at the time of injury had been pain and anger $(\mathrm{M} \pm \mathrm{SD} 3.69 \pm 1.32)$.

\section{Social support}

The active players' families offered the highest level of social support $(\mathrm{M} \pm \mathrm{SD} 4.35 \pm 0.87)$, followed by the club's physiotherapist ( $\mathrm{M} \pm \mathrm{SD} 4.12 \pm 1.24)$. Teammates and partners also achieved high scores, while the coaching SMs' scores were deficient $(\mathrm{M} \pm \mathrm{SD} 2.55 \pm 1.41)$.

The highest level of satisfaction with social support (Table 3) was reported for family members $(\mathrm{M} \pm \mathrm{SD}$ $4.5 \pm 0.87)$ and the lowest for coaches $(\mathrm{M} \pm \mathrm{SD} 2.98 \pm 0.51)$, while the support from teammates was relatively high $(\mathrm{M} \pm \mathrm{SD} 3.7 \pm 0.38)$. The support from the strength and conditioning coach $(\mathrm{M} \pm \mathrm{SD} 3.3 \pm 0.31)$ was much higher than that from the head coach $(\mathrm{M} \pm \mathrm{SD} 3.0 \pm 0.51)$.

In general, the players evaluated the satisfaction with all 3 types of social support (emotional, tangible, and infor- 
Table 3. Satisfaction of female elite handball players $(\mathrm{N}=51)$ with social support from their families, teammates and coaching staff during the injury recovery period (from 6 - very satisfied to 1 - very dissatisfied) in the study on assessing the injury recovery and social support among elite female handball players from the European Champions League, the University of Ljubljana, Slovenia, 2017-2021

\begin{tabular}{lc}
\hline \multicolumn{1}{c}{ Supporting person } & $\begin{array}{c}\text { Satisfaction } \\
(\mathrm{M} \pm \mathrm{SD})\end{array}$ \\
\hline Family & $4.55 \pm 0.87$ \\
Teammates & $3.72 \pm 0.86$ \\
All coaching staff & $3.28 \pm 0.74$ \\
$\quad$ head coach & $2.89 \pm 0.51$ \\
strength and conditioning coach & $3.28 \pm 0.31$ \\
physiotherapist & $4.12 \pm 0.31$ \\
\hline
\end{tabular}

mational) on a 1-6-point scale ranging 2.67-4.8 (Table 4), which means that the level of satisfaction was good, but not as high as it would be expected according to the club's reputation in elite handball. At nearly all levels, the players evaluated family support with the highest scores (3.2-4.8). Only for informational support, the rates were higher for the psychotherapist (4.2) and teammates (3.5) than for family members (3). The players were satisfied the most with the emotional $(\mathrm{M} \pm \mathrm{SD} 4.8 \pm 0.863)$ and tangible ( $\mathrm{M} \pm \mathrm{SD} 4.8 \pm 0.87$ ) support from family members, but dissatisfied with the head coach's support $(\mathrm{M} \pm \mathrm{SD} 2.90 \pm 0.59)$.
The physiotherapist provided a high level of all types of support $(\mathrm{M} \pm \mathrm{SD} 4.2 \pm 0.62)$, and the strength and conditioning coach had high scores as well $(\mathrm{M} \pm \mathrm{SD} 3.9 \pm 0.72)$.

An important part of the study was to evaluate the satisfaction with environmental factors (Table 5). The active players were very satisfied $(\mathrm{M} \pm \mathrm{SD} 4.6 \pm 0.86)$ with physical factors (fitness, SPAs, equipment), and a little less $(\mathrm{M} \pm \mathrm{SD} 4.4 \pm 0.80)$ with institutional support (insurance, salary) in the studied environment. The rates were high, but not quite following the opinion of the former players who rated environmental factors as optimal, close to ideal for elite sport.

\section{Former players}

The former players first agreed that in the active career, their approach to injuries was more emotional and that they were extremely demanding when seeking social support. Former player 2: "When I was injured, I felt vulnerable and sorry for myself. I was waiting for others to solve my problem." Similarly to the active players' answers, the former players also mentioned excellent environmental factors in the said club (excellent conditions for the career, excellent management, a good salary, good coaching staff, insurance), especially during the injury recovery process (different therapies, possibilities to get a second medical opinion, sauna, physiotherapy, mas-

Table 4. Satisfaction of female elite handball players with emotional, tangible and informational support (from 6 - very satisfied to 1 - very dissatisfied) in the study on assessing the injury recovery and social support among elite female handball players from the European Champions League, the University of Ljubljana, Slovenia, 2017-2021

\begin{tabular}{lccc}
\hline \multirow{2}{*}{\begin{tabular}{c} 
Supporting person \\
\cline { 2 - 4 }
\end{tabular}} & \multicolumn{2}{c}{$\begin{array}{c}\text { Satisfaction } \\
(\mathrm{M} \pm \mathrm{SD})\end{array}$} \\
\cline { 2 - 4 } & emotional & tangible & informational \\
\hline Family & $4.8 \pm 0.86$ & $4.8 \pm 0.80$ & $3.28 \pm 0.60$ \\
Teammates & $4.1 \pm 0.79$ & $4.2 \pm 0.82$ & $3.5 \pm 067$ \\
Head coach & $2.90 \pm 0.59$ & $2.90 \pm 0.56$ & $2.90 \pm 0.57$ \\
Strength and conditioning coach & $3.5 \pm 0.86$ & $3.90 \pm 0.25$ & $3.5 \pm 0.72$ \\
Physiotherapist & $4.1 \pm 0.45$ & $4.1 \pm 0.52$ & $4.1 \pm 0.62$ \\
\hline
\end{tabular}


sages, etc.). Having also gained experience in other clubs, the former players underlined that the conditions in the said club were better than anywhere else in Europe. Former player 4: "More than elsewhere, our president was dedicated to our club. He took care of everything, visited injured players at the hospital, and even called my parents to inform my family about my status."

The former players wholeheartedly believed that social support could improve and shorten the recovery process. They also pointed out that faster recovery would have been even more pronounced if they had been more aware of the optimal environmental factors and kept a positive attitude without losing focus when complaining. Former player 5: "I am sorry that nobody led us through the process, informed us... This was missing. We had unrealistically high demands. If I had been aware of what ideal conditions we had, it would have helped me to recover faster." The idea of a new coaching SM originated from such statements.

The former players also recollected missing support from coaches during the active career, although they changed their opinion later on. Former player 3: "Retrospectively, I completely changed my perspective. In my active career, I was judging my coach a lot, but nowadays I know that the coach feels the worst in the situations when a player is injured." The players also admitted having the possibility of consulting a psychologist, but that person's role did not have the desired effect. Such statements confirm the opinion that, in the process of injury recovery, basic psychological education is not sufficient for the position.

\section{Coaching SMs}

The general finding is that the coaching SMs were reserved in expressing their views and observations. It was obvious that the coaching SMs had very different experience, some even quite negative. They needed repeated reassurances that the data were a matter of scientific research and that nobody would be directly informed about their responses.
Table 5. Satisfaction of active elite handball players ( $N=51)$ with environmental factors (from 6 - very satisfied to 1 - very dissatisfied) in the study on assessing the injury recovery and social support among elite female handball players from the European Champions League, the University of Ljubljana, Slovenia, 2017-2021

\begin{tabular}{lc}
\hline \multicolumn{1}{c}{ Environmental factor } & $\begin{array}{c}\text { Satisfaction } \\
(\mathrm{M} \pm \mathrm{SD})\end{array}$ \\
\hline $\begin{array}{l}\text { Physical factors (facilities: SPAs, gyms; } \\
\text { equipment for injury prevention } \\
\text { and recovery) }\end{array}$ & $4.6 \pm 0.86$ \\
\begin{tabular}{l} 
Institutional factors (insurance, salary) \\
\hline
\end{tabular} & $4.4 \pm 0.80$ \\
\hline
\end{tabular}

The head coach reported negative experience with some players who took the social support which was offered to them for granted and did not express any gratitude or solidarity with the situation. The strength and conditioning coach and the physiotherapist also shared some similar negative experiences. Coaching SM 2: "Some players intentionally prolonged the process of returning to full activity, going beyond all reason, because they were selfcentered and had no empathy for the rest of the team." All coaching SMs, on the other hand, also mentioned many extremely dedicated players, who stayed positive, motivated and cooperative. Coaching SM 3: "In general, players had a lot of self-motivation, as their actions were motivated by the desire to rejoin their team as quickly as possible." The responses indicate that the coaching SMs considered providing social support (too) demanding, which could even lead to internal conflicts between focusing on the team's performance and results, and trying to provide sufficient support to injured players. Coaching SM 1: "If you deal with injured players too much, you can find yourself in a loop... and become an 'ex-coach' very soon. As a coach, you are under stress all the time. This has to be solved differently." The next problem for coaches was the feeling of not being competent enough. Coaching SM 1: "We, coaches, are not equipped with the skills to provide high-quality, systematic support. You know that 
a 'how-are-you-doing conversation' is just not enough, but you, as a person, are depressed about not having the possibility of helping more. In elite sport, you have to be totally focused on active players, with whom you have to win." The players highlighted the role of the head coach in the last phase of recovery - a (fast) return to active playing, when the support of the coach was considered vital.

The coaching SMs were aware of being torn between providing social support and being focused on top performance and the final ranking which is probably the main priority in professional sport. They agreed that the problem should be solved differently.

When asked to evaluate environmental factors, the coaching SMs described the conditions in the studied club environment and in the studied period as excellent. Coaching SM 2: "We had everything that was needed for optimal recovery. I had a direct, 24-hour link to the medical staff at the University Medical Centre so that every injury was treated in the shortest possible time." All the coaching SMs also mentioned excellent equipment for prevention training and recovery at the club, and many special training camps. They regretted that those excellent conditions were taken for granted and not fully used by the players. All the coaching SMs became even more aware of the club's favorable conditions when they migrated to some other clubs.

\section{DISCUSSION}

According to these findings and other similar studies [812 ], the most common injuries in professional handball are sprains, and the most prolonged absences from training and competitions are caused by knee injuries, which can last $\leq 10$ months (practically the whole season). Studies in modern professional sports [4-6] present social support as an important factor for a faster injury recovery process. The level of satisfaction with the general level of social support was good, but not as high as it would be expected, while informational support did not reach the level of excellent environmental conditions. The findings presented in this study emphasize the role of the head coach in providing social support, which is in accordance with the findings of some other studies [21,26], and show a difference in the perception of social support during injury recovery between the coaching SMs and the active players. The coaching SMs pointed out (and the former players fully agreed) that the active players' expectations of their support were too high, and that providing adequate social support in injury recovery exceeded both the coaches' capacities and competences.

The verbal or non-verbal requirements of active players in the injury recovery process can lead to coaches experiencing inner conflicts knowing that their basic focus should remain on the team's performance while also being aware of the need to be supportive towards injured players. The results indicate a need for a better coordination of social support in the injury recovery process.

In some sports environments, the injury recovery process is not so closely connected to coaches and teams, but it remains more within the domain of medical staff. In football, the person who leads the recovery process is called the Head Medical Officer [26]. As this is not the case in professional handball and as several studies confirm that providing support to players in injury recovery can be a burden for coaches [21,26], handball teams would need an expert with several different competences (medicine, physical therapy, mental coaching, and elite [team] sports background) who would contribute to faster recovery and general well-being of professional handball players. Different perceptions of social support can lead to conflict situations in the team, and to the deterioration of cooperation and relationships between players and coaching SMs, which can have negative consequences for the whole club environment. Strained relationships frequently result in the prolongation of the injury recovery process. Even minor conflict situations between players and the coaching staff affect team spirit, which is then reflected in 
the team's performance. New findings [28,29] about occupational stress and social support suggest that all team members should foster team cultures that support mental health and general well-being in the team.

\section{CONCLUSIONS}

This study advances the understanding of the occupation of a professional female handball player in the injury recovery process in terms of both the injury characteristics and social support. Professional players believe that the appropriate social support can improve and shorten the injury recovery process. The former players underlined excellent environmental factors and an unrealistic evaluation of the environment and social support during their active career. The active players were very satisfied with the social support from their families, but dissatisfied with the support from their coaches. Providing social support evidently creates much pressure and represents a significant burden for coaches, which leads to a conclusion that professional clubs would need to establish a new position for an expert with interdisciplinary competencies (in the fields of sport, medicine, physical therapy, psychotherapy, coaching, physical preparation, etc.) who would assume the role of a coordinator. The main conclusion can also serve as a springboard for further investigation into establishing this new position, which would contribute to faster recovery and general wellbeing of professional female handball players.

\section{REFERENCES}

1. International Labour Organisation [Internet]. Standards Classification of occupations ISCO-08 Geneva. International Labour Office; 2012 [cited 2020 Mar 12]. Available from: https://www.ilo.org/wcmsp5/groups/public/---dgreports/--dcomm/---publ/documents/publication/wcms_172572.pdf.

2. Lentz L, Voaklander D, Gross DP, Guptill CA, Senthilselvan A. A description of musculoskeletal injuries in a Canadian police service. Int J Occup Med Environ Health. 2020;33(1):59-66, https://doi.org/10.13075/ijomeh.1896.01454.
3. Tranæus U, Ivarsson A, Johnson U. Stress and Injuries in professional sport. In: Fuchs R, Gerber M, editors. Handbuch Stressregulation und Sport. Berlin: Springer-Verlag GmbH Deutschland; 2018. p. 451-66. German.

4. Laver L, Landreau P, Seil R, Popovic N, editors. Handball Sports medicine. Berlin, Heidelberg: Springer; 2018.

5. Kraemer W, Denegar C, Flanagan S. Recovery from injury in sport, considerations in the transition from medical care to performance care. Sports Health. 2009;1(5):392-5, https:// doi.org/10.1177/1941738109343156.

6. Ardern CL, Österberg A, Tagesson S, Gauffin H, Webster KA, Kvist J. The impact of psychological readiness to return to sport and recreational activities after anterior cruciate ligament reconstruction. Br J Sports Med. 2014;48(22):1613-9, https://doi.org/10.1136/bjsports-2014-093842.

7. Ardern, CL, Webster KE, Taylor NF, Feller JA. Return to Sport following anterior cruciate ligament reconstruction surgery: a systematic review and meta-analysis of the state of play. Br J Sports Med. 2011;45(7):596-606, https://doi.org/ 10.1136/bjsm.2010.076364.

8. Curitianu IM. Injuries and their prevention in the handball game. J Social Sci Res. 2015;7(2):1271-5, https://doi.org/10. 24297/jssr.v7i2.3570.

9. Weber J, Wegner M. Psychological aspects in Handball Injuries. In: Laver L. Landreau P, Seil R, Popovic N, editors. Handball Sports medicine. Berlin, Heidelberg: Springer; 2018. p. 639-50.

10. Bere T, Bahr R, Popovic N. Mechanisms of Injuries in Handball. Aspetar Sports Med J. 2014;3:142-7.

11. Myklebust G, Bahr R, Nilstad A, Steffen K. Knee function among professional handball and football players 1-6 years after anterior cruciate ligament injury. Scand J Med Sci Sports. 2017;27(5):545-53, https://doi.org/10.1111/sms.12842.

12. Olsen OE, Myklebust G, Engebretsen L, Bahr R. Injury mechanisms for anterior cruciate ligament injuries in team handball: a systematic video analysis. Am J Sports Med. 2014;32:1002-12, https://doi.org/10.1177/0363546503261724.

13. Ardern, CL, Webster KE, Taylor NF, Feller JA. Return to Sport following anterior cruciate ligament reconstruction 
surgery: a systematic review and meta-analysis of the state of play. Br J Sports Med. 2011;45(7):596-606, https://doi.org/ 10.1136/bjsm.2010.076364.

14. Tracey J. The emotional response to the injury and rehabilitation process. J Appl Sport Psy. 2003;15(4):279-93, https:// doi.org/10.1080/714044197.

15. Schaefer K, Coyne JC, Lazarus RS. The health orientated functions of social support. J Behav Med. 1981;4(4):381406, https://doi.org/10.1007/bf00846149.

16. Brewer BW, Andersen MB, Van Raalte JL. Psychological aspects of sport injury rehabilitation: Toward a bio psychosocial approach. In Mostofsky D, Zaichkowsky LD, editors. Medical and psychological aspects of sport and exercise. Morgantown WV: Fitness Information Technology; 2002. p. 41-54.

17. Hardy CJ, Crace RK. The dimensions of social support when dealing with sport injuries. In: Pargman D, editor. Psychological bases of sport injury. Morgantown WV: Fitness Information Technology; 1993. p. 121-44.

18. Sarason, IG, Levine HM, Basham RB, et al. Assessing social support: The Social Support Questionnaire. J Person Social Psych. 1983;44:127-39.

19. Cutrona CE, Russell DW. Type of social support and specific stress: toward a theory of optimal matching. In: Sarason BR, Sarason IG, Pierce GR, editors. Social support: An interactional view. New York: Wiley; 1990. p. 319-66.

20. Clement D, Shannon VR. Injured athletes' perceptions about social support. J Sport Rehab. 2011;20(4):457-70.

21. Maurice S, Kuklic C, Andresen M. Providing social support to injured athletes: Applications of the International Sport Coaching Framework. Int J Phy Educ Sports Health. 2017;4(5):166-75.

22. Bianco T, Eklund R. Conceptual Considerations for Social Support Research in Sport and Exercise Settings: The Case of Sport Injury. J Sport Exer Psych. 2001;23:85-107, https:// doi.org/10.1123/jsep.23.2.85.

23. Fernandes HM, Machado Reis V, Vilaça-Alves J, Saavedra F, Aidar FJ, Brustad R. Social support and sport injury recovery: An overview of empirical findings and practical implications. Rev Psicol Deporte. 2014;23(2):445-9.

24. Barrera M, Sandler IN, Ramsay TB. Preliminary Development of a Scale of Social Support: Studies on College Students. Amer J Commun Psych. 1981;9(4):435-47, https://doi. org/10.1007/BF00918174.

25. Cunliffe M, Walker N. The coaches' role in athlete injury rehabilitation: The athletes' perspective. An overview of the athletes perspectives on the coaches role during injury rehabilitation. Manchester: Division of Sport and Exercise Psychology Conference; 2013.

26. McCall A, Dupont G, Ekstrand J. Injury prevention strategies, coach compliance and player adherence of 33 of the UEFA professional Club Injury Study teams: a questionnaire of teams' head medical officers. Br J Sports Med. 2016;50:72530, https://doi.org/10.1136/bjsports-2015-095259.

27. Galli N. Psychosocial Health and Well-being in High-Level Athletes. New York: Rouledge; 2019.

28. Knights S, Ruddock-Hudson M. Experiences of occupational stress and social support in Australian Football League senior coaches. Int J Sports Sci Coach. 2016;11:162-71, https:// doi.org//10.1177/1747954116636711.

29. Bissett JE, Kroshus E, Hebard S. Determining the role of sport coaches in promoting athlete mental health: a narrative review and Delphi approach. BMJ Open Sp Ex Med. 2020;6:e000676, https://doi.org/10.1136/bmjsem-2019-000676.

30. Hill CE, Thompson BJ, Williams EN. A guide to consensual qualitative research. Counsel Psychol. 1997;25:517-72, https://doi.org/10.1177/0011000097254001.

This work is available in Open Access model and licensed under a Creative Commons Attribution-NonCommercial 3.0 Poland License - http://creativecommons.org/ licenses/by-nc/3.0/pl/deed.en. 